\title{
REVIEW
}

\section{Minimizing the Risk of Hypoglycemia with Vildagliptin: Clinical Experience, Mechanistic Basis, and Importance in Type 2 Diabetes Management}

\author{
Sylvie Dejager · Anja Schweizer
}

Received: October 20, 2010 / Published online: February 8, 2011

(c) The Author(s) 2011. This article is published with open access at Springerlink.com

\section{ABSTRACT}

Even if the true incidence of hypoglycemia in type 2 diabetes mellitus (T2DM) remains difficult to estimate, with highly variable rates reported in the literature, it is likely more common than previously thought. While most hypoglycemic episodes in T2DM are considered "mild," they still have a substantial clinical impact. Severe hypoglycemia also exists in T2DM, with recent landmark studies prompting much debate about the potential role of severe hypoglycemia in cardiovascular morbidity and mortality, even though there is currently no definitive evidence for causality. The challenge in the treatment of T2DM remains the achievement of optimal glycemic control to lower the risk for long-term complications while avoiding hypoglycemia. Successful treatment strategies should therefore include careful selection of therapies to prevent

Sylvie Dejager $(\square)$

Novartis Pharma S.A.S., Clinical Research \&

Development, 2/4, Rue Lionel Terray, F-92500 Rueil-

Malmaison, France. Email: sylvie.dejager@novartis.com

Anja Schweizer

Novartis Pharma AG, Postfach, CH-4002 Basel,

Switzerland hypoglycemia, starting early in the disease management process, in order to best preserve counterregulation. The dipeptidyl peptidase- 4 inhibitor, vildagliptin, is a good treatment option to minimize the risk of hypoglycemia over time, while maintaining good glucose control. Extensive clinical experience is available for vildagliptin, with data published for all stages of the condition and with the low hypoglycemic potential stemming from a solid mechanistic basis.

Keywords: hypoglycemia; type 2 diabetes mellitus; vildagliptin

\section{DEFINITION, FREQUENCY, AND SEVERITY OF HYPOGLYCEMIA IN TYPE 2 DIABETES MELLITUS: THE SCOPE OF THE PROBLEM}

Hypoglycemia is a common problem in patients with type 2 diabetes mellitus (T2DM), occurring most frequently with medications that raise insulin levels independently of blood glucose, such as oral insulin secretagogues (sulfonylureas and glinides) and exogenous insulin. Unfortunately, there is no consensus definition of hypoglycemia in diabetes, ${ }^{1}$ 
and no standard definition of hypoglycemia has been used in clinical trials, making it difficult to assess its incidence, with substantial variation in reported rates. ${ }^{2}$ The American Diabetes Association (ADA) Workgroup on Hypoglycemia $^{3}$ defined hypoglycemia as "any abnormally low plasma glucose concentration that exposes the subject to potential harm" with a proposed threshold of plasma glucose $<70 \mathrm{mg} / \mathrm{dL}(<3.9 \mathrm{mmol} / \mathrm{L})$, with or without symptoms, below which the neuroendocrine counterregulatory response is physiologically activated, prompting the behavioral defense of rapid carbohydrate ingestion. The European Medicines Agency (EMA), on the other hand (in the 2006 note for guidance on clinical investigation of medicinal products in the treatment of diabetes mellitus), recommended a lower threshold of plasma glucose $(<3 \mathrm{mmol} / \mathrm{L})$ to define hypoglycemia when assessing the hypoglycemic risk of different treatment regimens, to allow for a more robust detection of clinically relevant hypoglycemia. ${ }^{1}$ Of note, most recent trials have consistently defined clinically severe hypoglycemia as any episode in which a patient is unable to self-treat, and thus requires the assistance of another person, making the data on severe hypoglycemia less subjective and, likely, more reliable. ${ }^{1,4}$

Mild hypoglycemic events, usually defined as self-treated episodes, are more common than severe hypoglycemia, but may be underreported since most patients do not spontaneously describe mild episodes at a physician/clinic visit, in part for fear of appearing unable to manage their condition. ${ }^{1}$ Since patients may be unreliable and likely to underestimate the frequency with which they experience hypoglycemia, patients' relatives and partners should also be questioned, to provide a more accurate record of hypoglycemic episodes. ${ }^{1,5,6}$ Despite these limitations, in recent
European Union observational studies, over one-third of patients reported having mild symptomatic episodes. ${ }^{7,8}$ The clinical consequences of mild hypoglycemia are not negligible in many ways, as further outlined below. In addition, recurrent mild hypoglycemic events lead to hypoglycemia unawareness; ie, patients' inability to perceive the normal warning symptoms of hypoglycemia. Indeed, antecedent hypoglycemia results in blunted neuroendocrine counterregulatory responses during subsequent hypoglycemia, leading to failure to sense future episodes. It has been recently shown that even one prior, relatively mild episode of hypoglycemia (of only $3.3 \pm 0.1$ $\mathrm{mmol} / \mathrm{L})$, may be sufficient to significantly blunt physiological defenses against subsequent hypoglycemia in modestly advanced T2DM, ${ }^{9}$ and increase the risk for subsequent severe hypoglycemia, perpetrating a vicious circle. ${ }^{2}$

Severe hypoglycemia becomes more frequent in the course of disease progression, with dysfunctional counterregulatory responses in advanced $\mathrm{T} 2 \mathrm{DM},{ }^{10,11}$ and it also increases with the duration of insulin treatment. ${ }^{12}$ An observational study by the UK Hypoglycaemia Study Group found that, for T2DM patients treated with insulin for $>5$ years, the prevalence of mild and severe hypoglycemia was similar to that for type 1 diabetic patients. However, even early insulin use in T2DM was associated with a substantial frequency of severe hypoglycemia (seen in $7 \%$ of patients followed for an average of 9 months), which was in fact similar to that observed in T2DM patients treated with sulfonylureas. ${ }^{13}$ With sulfonylureas, the risk for severe hypoglycemia markedly increases with age and with decreasing renal function. Patients treated with sulfonylureas from the comprehensive community-based database of the Diabetes Audit and Research in Tayside Scotland (DARTS)/Medicines Monitoring Unit (MEMO) 
collaboration experienced very severe events (defined as requiring emergency treatment from primary care, ambulance services, and hospital accident and emergency departments) with an annual rate of $0.8 \% .{ }^{14}$

In the more recent, Real-Life Effectiveness and Care Patterns of Diabetes Management (RECAP-DM) observational, cross-sectional study conducted in seven European countries over 1 year, about $5 \%$ to $6 \%$ of patients with T2DM on oral therapy experienced severe hypoglycemic episodes requiring assistance. ${ }^{7}$ In another observational, cross-sectional, multicenter study conducted in France, ${ }^{8} 4 \%$ of patients treated with a combination of metformin and sulfonylurea reported severe hypoglycemia over 6 months. In addition, it is worth noting that sylfonylureas are not all equivalent in terms of hypoglycemic risk, with older sylfonylureas having longer time-action characteristics, such as glyburide (glibenclamide) or chlorpropamide, being associated with greater risk than the second- and third-generation agents, such as gliclazide and glimepiride. ${ }^{1}$ Even among the latter, the GlUcose control in type 2 diabetes: Diamicron modified release (MR) versus glimEpiride (GUIDE) study showed that gliclazide MR, while being as effective as glimepiride, was associated with significantly fewer confirmed hypoglycemic episodes, in comparison with glimepiride. ${ }^{15}$ This adds to the heterogeneity in the estimates of the prevalence of hypoglycemia reported across epidemiological studies.

\section{CLINICAL CONSEQUENCES OF HYPOGLYCEMIA}

Hypoglycemia is associated with many adverse consequences that may, in some cases, counterbalance the benefit of a strict glycemic control. The most important aspects are described below.
Even Mild Events Have a Detrimental Effect, Creating a Barrier to Long-Term Glycemic Control

While severe hypoglycemic events can clearly have dramatic consequences, especially in older, more vulnerable patients, even trivial events represent a significant psychological burden to patients and an important limiting factor in disease management. For patients, there is indeed no such thing as a "mild" hypoglycemic event in terms of effects and consequences. On the one hand, it can lead to reduced willingness to take medication as prescribed (reducing or omitting doses). On the other hand, it is often associated with decreased adherence to diet (with "defensive eating" and snacking to prevent and/ or correct hypoglycemia) and exercise avoidance. These behavior changes both ultimately translate into weight gain, countering the main lifestyle message in T2DM management in an environment where an estimated $80 \%$ to $90 \%$ of patients need to lose weight. ${ }^{16}$

\section{Impact of Fear}

In balancing the urge to avoid the acute effects of hypoglycemia and the need to prevent longterm complications, immediate unpleasant consequences can be more important to patients than future complications. ${ }^{6}$ The symptoms and negative consequences associated with hypoglycemia, as well as the higher level of variability in blood glucose levels, or the need for assistance, may result in major anxiety and fear of hypoglycemia, which have significant clinical implications for diabetes management. ${ }^{6,17}$ Fear of hypoglycemia impacts on well-being and quality of life, and reduces treatment satisfaction and adherence to diabetes therapies. ${ }^{7,18-20}$ A study conducted in Cardiff, UK, using data from postal surveys among subjects with confirmed 
diabetes, ${ }^{20}$ showed that hypoglycemia was associated with a considerable decrement in health-related utility (using the EuroQol 5 Dimensions [EQ-5D] index) as a function of increased fear. The RECAP-DM study further showed that hypoglycemia was associated with significantly lower treatment satisfaction, and a number of barriers to treatment adherence. ${ }^{7}$

\section{Impact of Hypoglycemia on Quality of Life}

Many studies have shown that hypoglycemia impacts heavily on the well-being and quality of life of people with diabetes; $;^{7,8,18,19}$ overall, quality of life decreased as the frequency and severity of hypoglycemia increased. Consistent with other studies, in the French observational study, ${ }^{8}$ hypoglycemia was associated with a significant reduction in quality of life, as measured with EQ-5D, which was apparent in the overall summary score and in the anxiety/depression and pain/discomfort scales.

\section{Impact of Hypoglycemia on Cost}

Data regarding the cost consequences of hypoglycemia are still scarce (most are from Sweden, Germany, France, and the UK), and clearly, more studies are needed. The available results, however, indicate that hypoglycemic events, especially severe episodes, lead to substantial direct and indirect costs of medical care and lost productivity. ${ }^{14,19,21-23}$ For example, in one UK study the cost of severe hypoglycemia due to T2DM (not including associated costs of any injury, disability, or work loss associated with the acute event) was estimated at around $£ 7.4$ million. ${ }^{14}$ Additionally, one study over a 6-week period showed that severe hypoglycemia resulted in the loss of a mean 8.6 productive days per T2DM patient. ${ }^{18}$ A German study has estimated that costs for hypoglycemia in T2DM are substantially higher than in type 1 diabetes, because of the longer length of hospital stay associated with older age, comorbidities, and polypharmacy. ${ }^{23}$

\section{Potential Link to Cardiovascular Morbidity and Mortality}

Other concerns regarding the consequences of hypoglycemia are linked to cardiovascular morbidity and mortality. ${ }^{24}$ Several mechanisms are potentially involved. Hypoglycemia has long been known as a risk factor for cardiac arrhythmia; ${ }^{25-27}$ a recent study ${ }^{28}$ showed that prior exposure to hypoglycemia led to impaired cardiovascular autonomic function, including decreased cardiac vagal baroreflex sensitivity, which may contribute to increased cardiovascular morbidity and mortality in patients with diabetes. Hypoglycemia has also been associated with cardiac ischemia ${ }^{29,30}$ and prothrombotic changes. ${ }^{31}$

There has recently been much debate around the puzzling findings of the Action to Control Cardiovascular Risk in Diabetes (ACCORD) study, ${ }^{2}$ which had brought to the headlines the question of the role of hypoglycemia in increasing the risk for cardiovascular events. Retrospective analysis of the study ${ }^{32}$ has confirmed that severe hypoglycemia was clearly associated with increased risk of death, even if this was true in both the intensive and conventional arms, and thus did not account for the difference in mortality observed between the two study arms. Higher mortality was actually seen in patients "resisting" to glucose control, with a lack of response to an intensified glucose control strategy. ${ }^{33}$

\section{Hypoglycemia in Vulnerable Populations: Elderly and Frail Patients}

In the elderly, symptoms of hypoglycemia can be particularly difficult to recognize, since elderly 
patients are more likely to have confusion, disorientation, or other neuroglycopeniarelated symptoms that can mimic other medical conditions. In addition, older T2DM patients have a marked subjective unawareness of hypoglycemia, an increased reaction time, and decreased ability to take corrective actions, which likely contribute to the increased probability of severe hypoglycemia reported in these patients. ${ }^{34}$ Furthermore, severe episodes in this age group are associated with more serious complications, including falls and significant mortality. ${ }^{1,35}$ A recent longitudinal cohort study in a population of older patients with T2DM, followed up for 27 years, showed that a history of single or multiple severe hypoglycemic episodes was associated with a subsequent graded increased risk of dementia (adjusted hazard ratio [HR] 1.94; 95\% confidence interval [CI] 1.42, 2.64 for patients with three or more episodes) independent of glycemic control, treatment, or comorbidities. ${ }^{36}$ On the whole, greater attention to the risk of hypoglycemia must be given when managing older patients with more advanced stages of T2DM.

\section{Need for Early Intervention with Special Attention to Minimizing Hypoglycemia}

When targeting optimized glycemic control, one should not only do it as early as possible in the course of the disease, but one should also try to minimize hypoglycemia from the start. Indeed, it is now well recognized that intensive therapy should best be implemented early in the course of the disease to capitalize on the so-called "legacy effect," as shown in the recently reported United Kingdom Prospective Diabetes Study (UKPDS) 10-year follow-up study. ${ }^{37}$ Likewise, it may be essential to avoid hypoglycemia very early on in the course of the condition, in the hope of best preserving counterregulation in the long run. ${ }^{9}$
A recent study showed that intensive oral combination therapy and antecedent hypoglycemia both produced widespread blunting of physiological defenses against subsequent hypoglycemia in a group of patients with relatively early T2DM (mean duration $\sim 6$ years).${ }^{9}$ After 6 months of aggressive glycemic control (with triple oral therapy) in this group of patients with very poor initial control (glycated hemoglobin $\left.\left[\mathrm{HbA}_{1 \mathrm{c}}\right] 10.2 \%\right)$, near normalization of $\mathrm{HbA}_{1 \mathrm{c}}(6.7 \%)$ resulted in an increased frequency to 3.2 for hypoglycemic episodes per patient month, with blunted sympatho-adrenal counterregulatory responses. ${ }^{9}$ Amiel and Cryer discussed these findings, and suggested that good control of diabetes be implemented as early as possible, but with special attention to minimizing hypoglycemia early in the disease process, to prevent loss of counterregulation. ${ }^{38}$

\section{CLINICAL EXPERIENCE WITH VILDAGLIPTIN AT ALL STAGES OF T2DM}

Dipeptidyl peptidase-4 (DPP-4) inhibitors bind and inhibit the enzyme that cleaves and inactivates the two principal incretins, glucagonlike peptide-1 (GLP-1) and gastric inhibitory polypeptide (GIP). Incretins are short-lived hormones released from the gut in response to food intake, and are responsible for the boost in insulin secretion that occurs following an oral glucose load. This occurs in a glucosedependent manner, unlike indiscriminate insulin secretagogues, such as sulfonylureas and glinides. This glucose-dependent "fail-safe" prevents even elevated incretin levels from overstimulating insulin secretion in the absence of elevated or rising glucose levels. Thus, incretinbased therapies are generally associated with a rather low hypoglycemic risk, and, due in part to less hypoglycemia-related defensive eating, 
they are also associated with weight neutrality. In contrast to GLP-1 receptor agonists, DPP-4 inhibitors prolong the activity and enhance the action of endogenous incretins, physiologically, at the time of their secretion. ${ }^{39}$

The DPP-4 inhibitor vildagliptin has been studied in a large clinical development program, showing good overall safety and tolerability, and improved glycemic control when given as monotherapy or combination therapy, with a low risk of hypoglycemia. Across all vildagliptin phase 3 studies, hypoglycemia was consistently defined as symptoms suggestive of low blood glucose ( $<3.1 \mathrm{mmol} / \mathrm{L}$ plasma glucose equivalent) confirmed by self-monitored blood glucose measurement. ${ }^{40}$ Severe hypoglycemia was defined as any episode requiring assistance by another party. Hypoglycemia data with vildagliptin are available across the T2DM spectrum, with particularly noteworthy results at both ends of the disease spectrum, as reviewed below.

\section{Vildagliptin Monotherapy in Prediabetes and Patients with Early Diabetes/Mild Hyperglycemia}

In nondiabetic (normal glycemic) individuals, vildagliptin does not stimulate insulin secretion, nor does it reduce glucose levels. However, the known effects of vildagliptin on incretin levels and islet function in T2DM are seen as early as in subjects with impaired glucose tolerance (IGT) or impaired fasting glucose (IFG). ${ }^{41,42} \mathrm{~A}$ 12-week study in 179 subjects with IGT exposed to vildagliptin $50 \mathrm{mg}$ once daily (q.d.) or placebo showed a $32 \%$ reduction in postprandial glucose excursions, with no evidence of hypoglycemia. ${ }^{41}$ Similarly, in a phase 3 study in patients with early T2DM and mild hyperglycemia (mean $\mathrm{HbA}_{1 \mathrm{c}}$ at baseline $6.7 \%$; $n=306$ ), who were thus at increased risk for hypoglycemia with anti-diabetic therapy, 1-year treatment with vildagliptin (50 mg q.d.) resulted in a significant $\mathrm{HbA}_{1 \mathrm{c}}$ difference of $-0.3 \%$ versus placebo, with no hypoglycemia reported in vildagliptin-treated patients. ${ }^{43}$ The lack of hypoglycemia is even more remarkable considering that approximately half $(n=144)$ of the randomized patients were $\geq 65$ years, a population known to be particularly susceptible to hypoglycemia. Moreover, no vildagliptintreated patients experienced hypoglycemia during a further 1-year extension study, despite continued improvement in glycemic control (significant difference of $0.5 \%$ vs. placebo), while two hypoglycemic events occurred in patients receiving placebo during the overall 2-year study period. $^{44}$

\section{Vildagliptin Monotherapy in the Broad T2DM Population}

Several phase 3 studies assessed vildagliptin monotherapy in patients with more advanced hyperglycemia than the studies discussed in the previous section, yet still drug naive (mean baseline $\mathrm{HbA}_{1 \mathrm{c}} 8.4 \%$ to $8.7 \%$ ). Across these eight monotherapy studies of 24 weeks to 2 years' duration, ${ }^{45-52}$ no severe hypoglycemia and a very low incidence of nonsevere episodes ( $0 \%$ to $0.7 \%$ with vildagliptin $100 \mathrm{mg} /$ day) was observed in vildagliptin-treated patients, despite robust improvements in $\mathrm{HbA}_{1 \mathrm{c}}$ of, on average, $\sim 1 \%$. Also of particular interest is an additional monotherapy study in elderly patients $\geq 65$ years of age (mean 71 years), in which the mean $\mathrm{HbA}_{1 \mathrm{c}}$ after 24 weeks was reduced to $7.1 \%$ with vildagliptin (100 mg q.d.) and 7.0\% with metformin (1500 mg/day) from a baseline $\mathrm{HbA}_{1 \mathrm{c}}$ of $7.8 \%$ and $7.7 \%$, respectively. ${ }^{53}$ Despite the low mean $\mathrm{HbA}_{1 \mathrm{c}}$ achieved at endpoint in this more vulnerable population, a low incidence of hypoglycemia was observed in both treatment groups, with no hypoglycemia reported in the vildagliptin-treated elderly 
patients, while two elderly patients receiving metformin experienced mild hypoglycemic episodes. ${ }^{53}$ A favorable hypoglycemia profile for vildagliptin in elderly patients was also seen in a pooled analysis of 374 drug-naive patients aged $\geq 65$ years (mean age 70 years) treated with vildagliptin monotherapy. ${ }^{54}$ While a robust $\mathrm{HbA}_{1 \mathrm{c}}$ reduction of $1.2 \%$ (baseline $8.3 \%$ ) was seen, hypoglycemia occurred in only $0.8 \%$ of the elderly vildagliptin-treated population, with all of the episodes considered mild. ${ }^{54}$

Recently, clinical experience with vildagliptin in a patient population with T2DM aged $\geq 75$ years has been published from a pooled analysis of phase 2 and 3 clinical trials, and no confirmed hypoglycemic events, including no severe events, were reported in this very elderly population. ${ }^{55}$

\section{Combination Therapy of Vildagliptin with Other Oral Anti-diabetic Agents (OAD)}

\section{Combination Therapy with Metformin}

Several phase 3 studies of 24 weeks to 2 years' duration evaluated vildagliptin as add-on therapy to metformin. Most of these studies had a mean baseline $\mathrm{HbA}_{1 \mathrm{c}}$ of approximately $8.4 \%$, and reported no severe hypoglycemia, and a very low incidence of nonsevere episodes ( $0.3 \%$ to $1.0 \%$ with vildagliptin $100 \mathrm{mg} /$ day), ${ }^{56-59}$ comparable to what was seen with monotherapy. Also, as described above for monotherapy, trials evaluating add-on therapy to metformin in T2DM patients who have mild hyperglycemia and are thus at increased risk for hypoglycemia with glucose-lowering treatment, are most relevant to assess the hypoglycemic potential of therapy. In such a study where the mean baseline $\mathrm{HbA}_{1 \mathrm{c}}$ was $7.3 \%$, a total of 2789 patients already receiving maximum tolerated doses of metformin were randomized to receive either vildagliptin (50 mg twice daily [b.i.d.]) or glimepiride (up to $6 \mathrm{mg} /$ day) for 1 year. ${ }^{60}$ While the efficacy was similar between the two treatment arms (noninferiority was achieved, with mean $\mathrm{HbA}_{1 \mathrm{c}} 6.75 \%$ and $6.71 \%$ at 1 year, respectively), vildagliptin was associated with significant reductions in the frequency and severity of hypoglycemia. Hypoglycemia occurred in $1.7 \%$ of vildagliptin-treated patients (39 episodes), compared to $16.2 \%$ of glimepiridetreated patients (554 episodes) $(P<0.01)$, with 0 versus 10 severe episodes $(P<0.01)$, and 0 versus 11 patients discontinuing study treatment because of hypoglycemia (Figure 1). ${ }^{60}$

These results were confirmed following an additional 1-year treatment period. ${ }^{61}$ Of note this benefit on hypoglycemia was also seen over a period of 2 years in a large group of elderly patients $(n=789)$, with $2.1 \%$ of patients experiencing at least one hypoglycemic event (18 events) in the vildagliptin group, versus $17.5 \%$ (202 events) of patients in the glimepiride group $(P<0.001) .{ }^{61}$ The neuroglucopenic symptoms associated with confirmed hypoglycemia occurred much less often with vildagliptin than glimepiride; there were no occurrences of confusional state/disorientation, vertigo/balance disorder/dystasia (unsteadiness)/ motion sickness, and malaise/syncope in patients treated with vildagliptin, compared with 34,45 , and 25 occurrences, respectively, with glimepiride (Table 1). ${ }^{61}$

Vildagliptin was also studied as initial combination therapy with metformin in drug-naive T2DM patients (baseline $\mathrm{HbA}_{1 \mathrm{c}}$ $8.7 \%$ ), with no hypoglycemic episodes reported with the fixed dose combination of vildagliptin and metformin (vildagliptin $50 \mathrm{mg}$ b.i.d., plus either low-dose [500 mg b.i.d.] or high-dose [1000 mg b.i.d.] metformin) over the 24-week treatment period, despite large reductions in $\mathrm{HbA}_{1 \mathrm{c}}$ of $1.6 \%$ and $1.8 \%$, respectively. ${ }^{52}$

Data with other DPP-4 inhibitors and GLP-1 analogs in combination with metformin confirm 
Figure 1. Incidence and severity of hypoglycemic events with vildagliptin and glimepiride during 1-year treatment (safety population; $n=1389$, vildagliptin group; $n=1383$, glimepiride group). ${ }^{60}{ }^{*} P<0.01$ between groups; b.i.d. $=$ twice daily; q.d.=once daily. Adapted with permission from: Ferrannini E, Fonseca V, Zinman B, et al. Fifty-two-week efficacy and safety of vildagliptin vs. glimepiride in patients with type 2 diabetes mellitus inadequately controlled on metformin monotherapy. Diabetes Obes Metab. 2009;11:157-166.

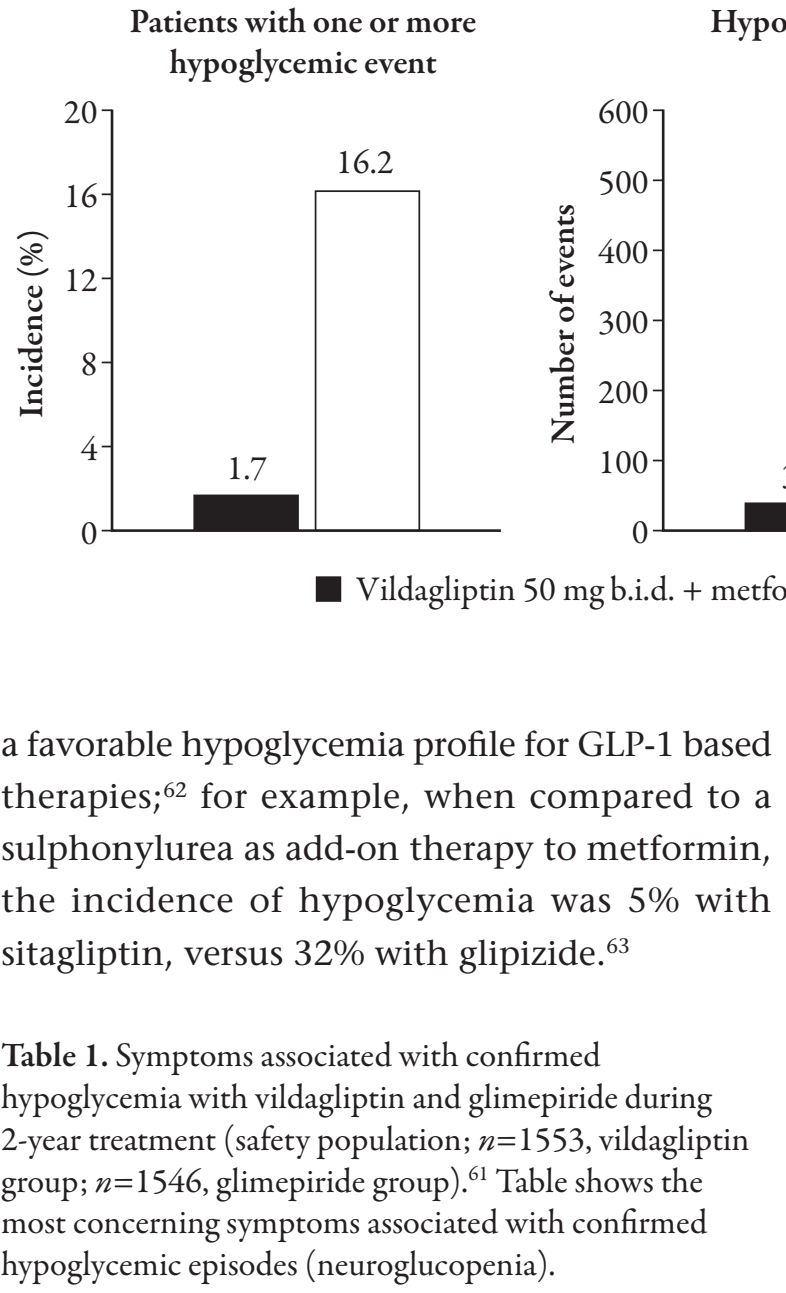

\begin{tabular}{lcc}
\hline & \multicolumn{2}{c}{ Number of occurrences } \\
\cline { 2 - 3 } Symptom & Vildagliptin & Glimepiride \\
\hline Confusion state/disorientation & 0 & 34 \\
Vertigo/balance disorders/ & & \\
unsteadiness & 0 & 45 \\
Malaise/syncope & 0 & 25 \\
Altered vision & 3 & 71 \\
\hline
\end{tabular}

Adapted with permission from: Matthews $D R$, Dejager $S$, Abren B, et al. Vildagliptin add-on to metformin produces similar efficacy and reduced hypoglycaemic risk compared with glimepiride, with no weight gain: results from a 2-year study. Diabetes Obes Metab. 2010;12:780-789.

\section{Combination Therapy with}

\section{Thiazolidinediones}

The incidence of hypoglycemia was also very low in patients receiving vildagliptin $(50 \mathrm{mg}$ q.d. or b.i.d.) added to pioglitazone ( $\leq 0.6 \%)$, and even somewhat lower than with placebo added to pioglitazone (1.9\%). ${ }^{64}$ There were no severe events reported. $\mathrm{HbA}_{1 \mathrm{c}}$ was reduced by up to $1.0 \%$ with vildagliptin in this 24 -week study.

A similar hypoglycemia profile was seen in an initial combination therapy study of vildagliptin and pioglitazone in drug-naive T2DM patients (baseline $\mathrm{HbA}_{1 \mathrm{c}}$ 8.7\%). ${ }^{46} \mathrm{HbA}_{1 \mathrm{c}}$ was reduced by 1.9\% (vildagliptin $100 \mathrm{mg}$ q.d. plus pioglitazone $30 \mathrm{mg}$ q.d.) and $1.7 \%$ (vildagliptin $50 \mathrm{mg}$ q.d. plus pioglitazone $15 \mathrm{mg}$ q.d.), respectively, with corresponding hypoglycemia incidences of $0.7 \%$ and $0 \%$; ie, only one mild episode reported. ${ }^{46}$

\section{Combination Therapy with Sulphonylureas}

When vildagliptin was added to a sulphonylurea (glimepiride $4 \mathrm{mg}$ q.d.) in a 24 -week study, $\mathrm{HbA}_{1 \mathrm{c}}$ decreased by $0.6 \%$ from an $8.5 \%$ baseline 
with both vildagliptin $50 \mathrm{mg}$ q.d. and $50 \mathrm{mg}$ b.i.d., versus an increase of $0.1 \%$ with placebo. ${ }^{65}$ The incidence of hypoglycemic events was low, but slightly higher in the group receiving vildagliptin $50 \mathrm{mg}$ b.i.d. (3.6\%) than in the group receiving vildagliptin $50 \mathrm{mg}$ q.d. (1.2\%) or placebo $(0.6 \%)$. All hypoglycemic episodes on vildagliptin therapy were mild, while there was one severe episode with placebo. ${ }^{65}$

In a second add-on to sulphonylurea study, vildagliptin $50 \mathrm{mg}$ b.i.d. or placebo were added to glimepiride (mean daily dose $2.5 \mathrm{mg}$ ) in Japanese patients. ${ }^{66}$ After 12 weeks of treatment, $\mathrm{HbA}_{1 \mathrm{c}}$ changes from a baseline of approximately $8 \%$ were $-1.0 \%$ with vildagliptin and $-0.06 \%$ with placebo. Despite the low $\mathrm{HbA}_{1 \mathrm{c}}$ at endpoint, the incidence of hypoglycemia was low ( $2 \%$ with vildagliptin $50 \mathrm{mg}$ b.i.d., and 1\% with placebo), and all events were mild (grade 1). ${ }^{66}$

Of note is that at the $\mathrm{HbA}_{1 \mathrm{c}}$ levels achieved through DPP-4 inhibition, the insulinotropic effects of endogenous GLP-1 are known to be strictly glucose dependent and, accordingly, hypoglycemia is rare when vildagliptin is given as monotherapy, or in combination with metformin or a thiazolidinedione. A potential explanation for the slightly higher incidence of hypoglycemia reported with vildagliptin and other DPP-4 inhibitors when given in combination therapy with sulphonylureas ${ }^{67}$ may be provided by a study by de Heer and Holst. ${ }^{68}$ It was found that sulphonylureas in the perfused rat pancreas appear to "uncouple" the glucose dependence of GLP-1's effects on pancreatic hormone secretion. ${ }^{68}$ Nonetheless, a study by El Ouaghlidi and colleagues ${ }^{69}$ demonstrated that in healthy volunteers, vildagliptin did not exacerbate the more serious hypoglycemia induced by sulphonylurea administration. The fact that all events were mild in the clinical studies of vildagliptin and sulphonylurea combination therapy in T2DM patients also suggests some degree of glucose dependency. ${ }^{65,66}$

In contrast, a marked increase in the risk of hypoglycemia has been reported when GLP-1 analogs are combined with sulphonylureas, ${ }^{70,71}$ and a reduction in the dose of sulphonylurea is generally recommended to reduce this risk. For example, the incidence of hypoglycemia was $14 \%$ and $36 \%$ with exenatide $5 \mu \mathrm{g}$ and $10 \mu \mathrm{g}$, respectively, added to sulphonylurea, compared to $3 \%$ for placebo added to sulphonylurea. ${ }^{70}$

GLP-1 is only glucose-sensitive at physiological GLP-1 concentrations, while at pharmacological GLP-1 levels, there is also a nonglucose-dependent stimulation of insulin secretion. ${ }^{72}$ DPP-4 inhibitors only prolong GLP-1 levels following nutrient-stimulated GLP-1 secretion, and therefore the physiological glucose-dependency of GLP-1 is preserved, while this may not be the case for GLP-1 analogs injected at pharmacological doses. Furthermore, with DPP-4 inhibitors, glucose-sensitive GIPstimulation of glucagon secretion may be maximized under hypoglycemia. ${ }^{73}$

\section{Combination Therapy with Insulin}

Hypoglycemia data of particular interest were obtained with vildagliptin in patients with advanced disease (mean diabetes duration $\sim 15$ years) receiving long-standing ( 6 years) insulin treatment. ${ }^{74,75}$ When vildagliptin $(50 \mathrm{mg}$ b.i.d.) was added to insulin monotherapy in patients with baseline $\mathrm{HbA}_{1 \mathrm{c}} 8.4 \%$ and mean daily insulin dose of $82 \mathrm{U}$, a reduction in $\mathrm{HbA}_{1 \mathrm{c}}$ of $0.5 \%$ from baseline was seen after 24 weeks $(P=0.01$ vs. placebo, with no change in insulin doses). ${ }^{74}$ Despite the greater reduction in $\mathrm{HbA}_{1 \mathrm{c}}$, hypoglycemic episodes were less frequent and less severe with vildagliptin treatment, compared to placebo. With vildagliptin added to insulin, 33 patients experienced a total of 113 events, while with placebo added to insulin, 45 patients 
experienced a total of 185 events. ${ }^{74}$ Importantly, there were six severe hypoglycemic events (requiring the assistance of another person) in the placebo-plus-insulin group, but no severe events in the vildagliptin-plus-insulin group (Figure 2) ${ }^{74}$ In a double-blind 28-week extension of the study, the hypoglycemia benefit was still evident. ${ }^{75}$

It is worth noting that no such reduction in hypoglycemia has been reported thus far with other DPP4-inhibitors in combination with insulin. In a clinical trial that investigated the addition of sitagliptin (100 mg q.d.) to insulin, an increased incidence of hypoglycemia (16\%) was reported with sitagliptin, compared with placebo (8\%), and there were two episodes with sitagliptin that met the protocol-specified criteria for severity, versus one such episode with placebo. ${ }^{76}$ While the reason for these different results remains to be further investigated, an interesting observation, which could provide a mechanistic basis, comes from a study by Marfella and colleagues ${ }^{77}$ in patients treated with metformin. In this study, the addition of vildagliptin (50 mg b.i.d.) was found to cause a more prolonged increase in active GLP-1 during the intraprandial period than the addition of sitagliptin (100 mg q.d.).

\section{REAL-LIFE EXPERIENCE}

The hypoglycemia profile described with vildagliptin in clinical studies is further supported by results from a "real-world" study, in which 52 Muslim patients with T2DM in north west London, UK, were followed during the Ramadan fasting period (no food or drink consumed from sunrise to sunset for a lunar month). Patients entered the observational period with $\mathrm{HbA}_{1 \mathrm{c}}>8.5 \%$ despite metformin treatment, and were given either vildagliptin $(50 \mathrm{mg}$ b.i.d., $n=26$ ) or gliclazide (160 mg b.i.d., $n=26$ ), starting 2 weeks prior to the fast. At approximately 10 days after the Ramadan fasting period, glycemic control was comparable in the two groups $\left(\mathrm{HbA}_{1 \mathrm{c}}\right.$ $7.7 \%$ with vildagliptin and $7.8 \%$ with gliclazide). However, hypoglycemia occurred in only two patients treated with vildagliptin, compared

Figure 2. Incidence and severity of hypoglycemic events in insulin-treated patients receiving vildagliptin versus placebo (safety population; $n=144$, vildagliptin group; $n=152$, placebo group). ${ }^{74}{ }^{*} P<0.001 ;{ }^{* *} P<0.05$ between groups. Adapted with permission from: Fonseca $V$, Schweizer A, Albrecht D, Baron MA, Chang I, Dejager $S$. Addition of vildagliptin to insulin improves glycaemic control in type 2 diabetes. Diabetologia. 2007;50:1148-1155.

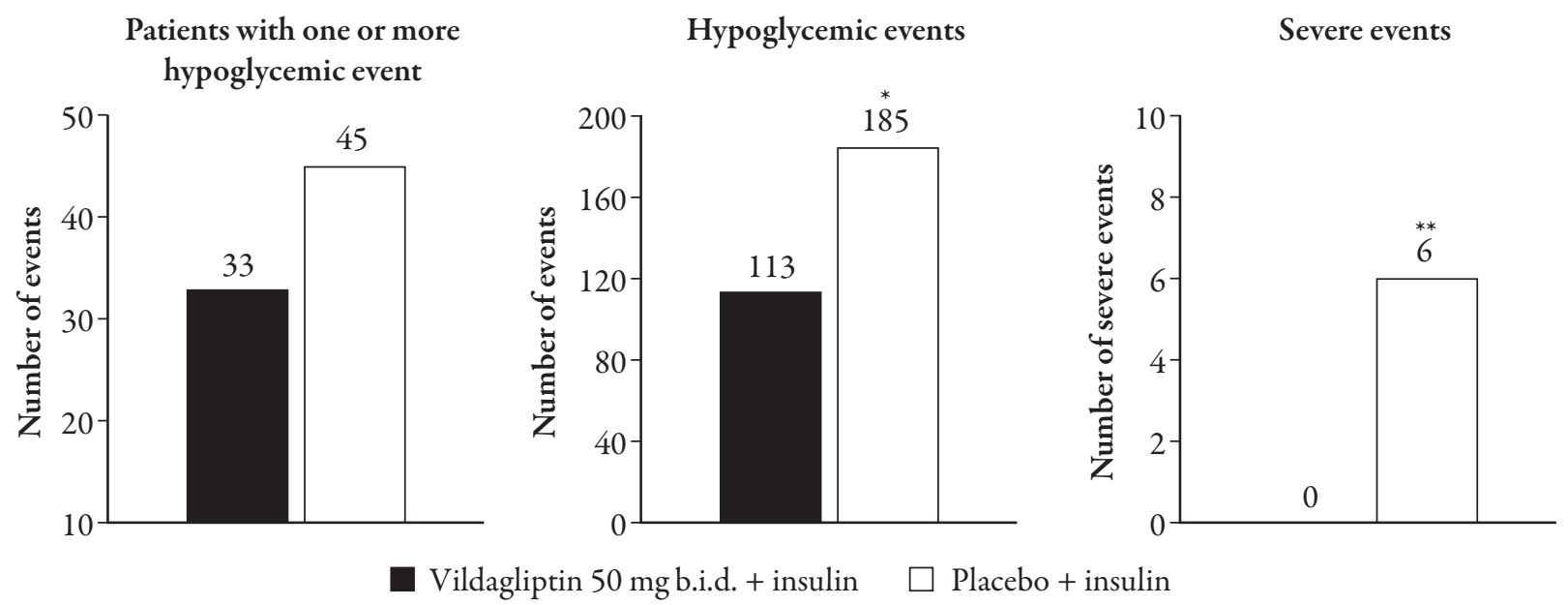


with 16 patients treated with gliclazide $(7.7 \%$ vs. $61.5 \%$, respectively; $P<0.001)$, with severe hypoglycemia occurring in one gliclazide-treated patient and in none of the vildagliptin-treated patients. $^{78}$

Taken together, vildagliptin treatment has consistently been associated with a low incidence of hypoglycemia in all clinical settings, including more vulnerable populations at higher risk for hypoglycemia, such as elderly patients or patients treated with insulin. This was again recently confirmed in a T2DM patient population $\geq 75$ years of age (based on a new pooled analysis of phase 2 and 3 clinical trials) in whom no confirmed hypoglycemic events, including no severe events, were reported..$^{55}$

This benefit stems from a solid mechanistic basis, including initial data suggesting that vildagliptin may enhance the glucagon response to hypoglycemia.

\section{MECHANISTIC BASIS FOR THE LOW RISK OF HYPOGLYCEMIA}

Among the glucose counterregulatory factors, glucagon plays a primary role, ${ }^{79}$ and even in modestly advanced T2DM, multiple defects already exist in hormonal responses to hypoglycemia, including delayed and reduced decreases in insulin secretion and impaired increases of plasma glucagon and growth hormone. ${ }^{80}$ Therefore, preserving this response is essential to minimize the risk of hypoglycemia with any given agent. It has previously been shown that, while metformin does not adversely affect the counterregulatory response to hypoglycemia, ${ }^{81}$ sulfonylureas significantly impair the glucagon response in T2DM patients. ${ }^{82}$ To evaluate whether vildagliptin would affect the hormonal counterregulatory response to hypoglycemia, the influence of 28-day treatment with vildagliptin (vs. placebo, in a double-blind crossover design) on the glucagon response to both hyper- and hypoglycemia was examined in patients with T2DM: standard breakfast meal tests were performed followed by stepped glucose clamps (7.5, 5.0, and $2.5 \mathrm{mmol} / \mathrm{L}$ glucose) ${ }^{83}$

This study showed that vildagliptin significantly increased (by 38\%) the glucagon increment during hypoglycemic clamp, yet reduced (by 41\%) the incremental postprandial glucagon area under the concentrationtime curve (AUC) $)_{0-60 \mathrm{~min}}$, thus improving both the action of glucose to suppress glucagon secretion during hyperglycemia (seen during meal ingestion), and the augmenting effect of hypoglycemia on glucagon secretion (seen during the stepped hypoglycemic clamp) (Figure 3). The effect could be mediated in part via the autonomic nervous system, because it was accompanied by enhanced stimulation of pancreatic polypeptide secretion (an index of vagal input to the pancreas). ${ }^{83}$

Additionally, the study found that the decrease in insulin secretion rate during hypoglycemia was more pronounced with vildagliptin than with placebo, being the first demonstration that a DPP-4 inhibitor enhanced the effectiveness of low glucose levels to suppress insulin secretion. ${ }^{83}$ While this observation would support the intra-islet hypothesis (the concept that glucagon secretion is essentially mediated by local insulin levels), it should be noted that vildagliptin was recently shown to exert its suppressive effect on glucagon secretion in the absence of endogenous insulin in insulinopenic patients with type 1 diabetes (thus independent of a paracrine effect of insulin). ${ }^{84}$ Furthermore, the glucagon response to hypoglycemia is now being investigated in insulin-treated patients with T2DM (ClinicalTrials.gov identifier: NCT01219400), and in type 1 diabetic patients treated with vildagliptin (ClinicalTrials.gov identifier: NCT01147276) in two studies. 
Figure 3. Glucagon response to hypoglycemia with vildagliptin versus placebo. ${ }^{83 *} P<0.05$ between groups. Adapted with permission from: Abrén B, Schweizer A, Dejager $S$, et al. Vildagliptin enhances islet responsiveness to both hyper-and bypoglycemia in patients with type 2 diabetes. J Clin Endocrinol Metab. 2009;94:1236-1243.

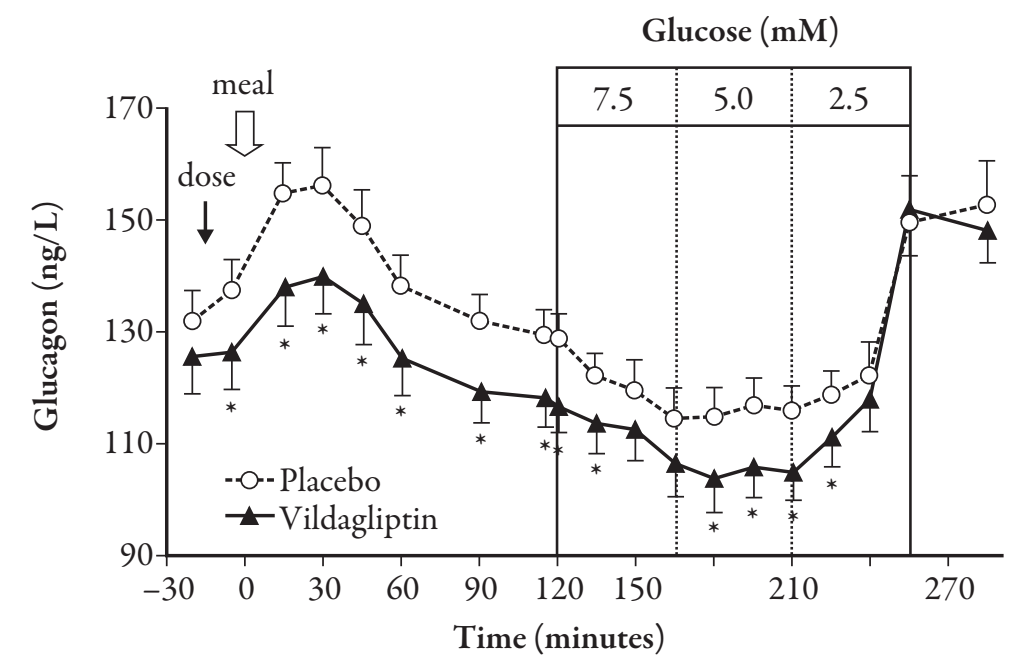

Hypoglycemia

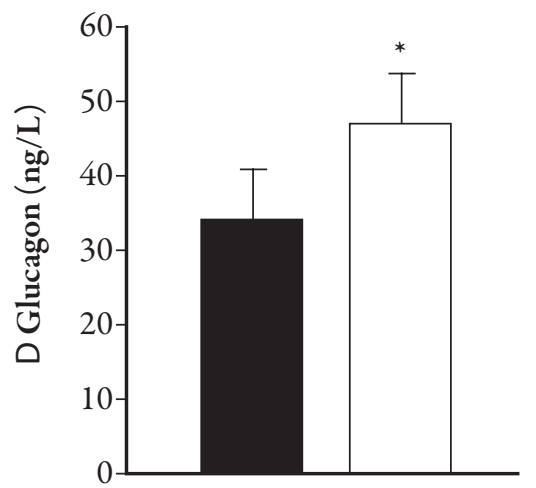

\section{CONCLUSION}

These initial mechanistic data provide evidence that DPP-4 inhibition with vildagliptin improves both $\alpha$ - and $\beta$-cell glucose sensing, augmenting the effects of hypoglycemia, both to stimulate glucagon release and to suppress insulin secretion. ${ }^{83}$ This may explain earlier findings that hypoglycemic episodes in patients with T2DM were less frequent and less severe with vildagliptin versus placebo added to insulin therapy. ${ }^{74,75}$ It may also explain the overall low risk of hypoglycemia with vildagliptin, which is extensively documented throughout the clinical development program across a wide range of clinical settings.

\section{ACKNOWLEDGMENTS}

The authors acknowledge the patients, investigators, and staff at participating sites for all the studies conducted with vildagliptin.

Sylvie Dejager is the guarantor for this article, and takes responsibility for the integrity of the work as a whole.
Open Access. This article is distributed under the terms of the Creative Commons Attribution Noncommercial License which permits any noncommercial use, distribution, and reproduction in any medium, provided the original author(s) and source are credited.

\section{REFERENCES}

1. Amiel SA, Dixon $\mathrm{T}$, Mann $\mathrm{R}$, Jameson $\mathrm{K}$. Hypoglycaemia in type 2 diabetes. Diabet Med. 2008;25:245-254.

2. Desouza CV, Bolli GB, Fonseca V. Hypoglycemia, diabetes, and cardiovascular events. Diabetes Care. 2010;33:1389-1394.

3. Workgroup on Hypoglycemia, American Diabetes Association. Defining and reporting hypoglycemia in diabetes: a report from the American Diabetes Association Workgroup on Hypoglycemia. Diabetes Care. 2005;28:1245-1249.

4. Barnett AH. Avoiding hypoglycaemia while achieving good glycaemic control in type 2 diabetes through optimal use of oral agent therapy. Curr Med Res Opin. 2010;26:1333-1342.

5. Heller S, Chapman J, McCloud J, Ward J. Unreliability of reports of hypoglycaemia by diabetic patients. BMJ. 1995;310:440. 
6. Wild D, von Maltzahn R, Brohan E, Christensen T, Clauson P, Gonder-Frederick L. A critical review of the literature on fear of hypoglycemia in diabetes: implications for diabetes management and patient education. Patient Educ Couns. 2007;68:10-15.

7. Alvarez GF, Tofe PS, Krishnarajah G, Lyu R, Mavros $\mathrm{P}$, Yin D. Hypoglycaemic symptoms, treatment satisfaction, adherence and their associations with glycaemic goal in patients with type 2 diabetes mellitus: findings from the Real-Life Effectiveness and Care Patterns of Diabetes Management (RECAPDM) Study. Diabetes Obes Metab. 2008;10(suppl. 1):25-32.

8. Vexiau P, Mavros P, Krishnarajah G, Lyu R, Yin D. Hypoglycaemia in patients with type 2 diabetes treated with a combination of metformin and sulphonylurea therapy in France. Diabetes Obes Metab. 2008;10(suppl. 1):16-24.

9. Davis SN, Mann S, Briscoe VJ, Ertl AC, Tate DB. Effects of intensive therapy and antecedent hypoglycemia on counterregulatory responses to hypoglycemia in type 2 diabetes. Diabetes. 2009;58:701-709.

10. Cryer PE. The barrier of hypoglycemia in diabetes. Diabetes. 2008;57:3169-3176.

11. Segel SA, Paramore DS, Cryer PE. Hypoglycemiaassociated autonomic failure in advanced type 2 diabetes. Diabetes. 2002;51:724-733.

12. Davis TM, Brown SG, Jacobs IG, Bulsara M, Bruce DG, Davis WA. Determinants of severe hypoglycemia complicating type 2 diabetes: the Fremantle diabetes study. J Clin Endocrinol Metab. 2010;95:2240-2247.

13. UK Hypoglycaemia Study Group. Risk of hypoglycaemia in types 1 and 2 diabetes: effects of treatment modalities and their duration. Diabetologia. 2007;50:1140-1147.

14. Leese GP, Wang J, Broomhall J, et al. Frequency of severe hypoglycemia requiring emergency treatment in type 1 and type 2 diabetes: a population-based study of health service resource use. Diabetes Care. 2003;26:1176-1180.

15. Schernthaner G, Grimaldi A, Di Mario U, et al. GUIDE study: double-blind comparison of oncedaily gliclazide MR and glimepiride in type 2 diabetic patients. Eur J Clin Invest. 2004;34:535542.

16. Pi-Sunyer FX. The impact of weight gain on motivation, compliance, and metabolic control in patients with type 2 diabetes mellitus. Postgrad Med. 2009;121:94-107.
17. Stargardt T, Gonder-Frederick L, Krobot KJ, Alexander CM. Fear of hypoglycaemia: defining a minimum clinically important difference in patients with type 2 diabetes. Health Qual Life Outcomes. 2009;7:91.

18. Davis RE, Morrissey M, Peters JR, Wittrup-Jensen $\mathrm{K}$, Kennedy-Martin T, Currie CJ. Impact of hypoglycaemia on quality of life and productivity in type 1 and type 2 diabetes. Curr Med Res Opin. 2005;21:1477-1483.

19. Lundkvist J, Berne C, Bolinder B, Jonsson L. The economic and quality of life impact of hypoglycemia. Eur J Health Econ. 2005;6:197-202.

20. Currie CJ, Morgan CL, Poole CD, Sharplin P, Lammert M, McEwan P. Multivariate models of health-related utility and the fear of hypoglycaemia in people with diabetes. Curr Med Res Opin. 2006;22:1523-1534.

21. Jonsson L, Bolinder B, Lundkvist J. Cost of hypoglycemia in patients with type 2 diabetes in Sweden. Value Health. 2006;9:193-198.

22. Allicar MP, Megas F, Houzard S, Baroux A, Le Thai F, Augendre-Ferrante B. Frequency and costs of hospital stays for hypoglycemia in France in 1995 [In French]. Presse Med. 2000;29:657-661.

23. Holstein A, Plaschke A, Egberts EH. Incidence and costs of severe hypoglycemia. Diabetes Care. 2002;25:2109-2110.

24. Wright RJ, Frier BM. Vascular disease and diabetes: is hypoglycaemia an aggravating factor? Diabetes Metab Res Rev. 2008;24:353-363.

25. Gill GV, Woodward A, Casson IF, Weston PJ. Cardiac arrhythmia and nocturnal hypoglycaemia in type 1 diabetes-the 'dead in bed' syndrome revisited. Diabetologia. 2009;52:42-45.

26. Landstedt-Hallin L, Englund A, Adamson U, Lins PE. Increased QT dispersion during hypoglycaemia in patients with type 2 diabetes mellitus. J Intern Med. 1999;246:299-307.

27. Lindstrom T, Jorfeldt L, Tegler L, Arnqvist HJ. Hypoglycaemia and cardiac arrhythmias in patients with type 2 diabetes mellitus. Diabet Med. 1992;9:536-541.

28. Adler GK, Bonyhay I, Failing H, Waring E, Dotson $S$, Freeman R. Antecedent hypoglycemia impairs autonomic cardiovascular function: implications for rigorous glycemic control. Diabetes. 2009;58:360-366. 
29. Campbell I. Dead in bed syndrome: a new manifestation of nocturnal hypoglycaemia? Diabet Med. 1991;8:3-4.

30. Desouza C, Salazar H, Cheong B, Murgo J, Fonseca V. Association of hypoglycemia and cardiac ischemia: a study based on continuous monitoring. Diabetes Care. 2003;26:1485-1489.

31. Dandona P, Chaudhuri A, Dhindsa S. Proinflammatory and prothrombotic effects of hypoglycemia. Diabetes Care. 2010;33:1686-1687.

32. Bonds DE, Miller ME, Bergenstal RM, et al. The association between symptomatic, severe hypoglycaemia and mortality in type 2 diabetes: retrospective epidemiological analysis of the ACCORD study. BMJ. 2010;340:b4909.

33. Boyko EJ. ACCORD glycemia results continue to puzzle. Diabetes Care. 2010;33:1149-1150.

34. Bremer JP, Jauch-Chara K, Hallschmid M, Schmid S, Schultes B. Hypoglycemia unawareness in older compared with middle-aged patients with type 2 diabetes. Diabetes Care. 2009;32:1513-1517.

35. Halimi S, Raccah D, Schweizer A, Dejager S. Role of vildagliptin in managing type 2 diabetes mellitus in the elderly. Curr Med Res Opin. 2010;26:1647-1656.

36. Whitmer RA, Karter AJ, Yaffe K, Quesenberry CP, Jr., Selby JV. Hypoglycemic episodes and risk of dementia in older patients with type 2 diabetes mellitus. JAMA. 2009;301:1565-1572.

37. Holman RR, Paul SK, Bethel MA, Matthews DR, Neil HA. 10-year follow-up of intensive glucose control in type 2 diabetes. N Engl J Med. 2008;359:15771589.

38. Amiel SA, Cryer PE. Attenuated sympathoadrenal responses, but not severe hypoglycemia, during aggressive glycemic therapy of early type 2 diabetes. Diabetes. 2009;58:515-517.

39. Deacon CF. Incretin-based treatment of type 2 diabetes: glucagon-like peptide-1 receptor agonists and dipeptidyl peptidase-4 inhibitors. Diabetes Obes Metab. 2007;9(suppl. 1):23-31.

40. Keating GM. Vildagliptin: a review of its use in type 2 diabetes mellitus. Drugs. 2010;70:2089-2112.

41. Rosenstock J, Foley JE, Rendell M, et al. Effects of the dipeptidyl peptidase-IV inhibitor vildagliptin on incretin hormones, islet function, and postprandial glycemia in subjects with impaired glucose tolerance. Diabetes Care. 2008;31:30-35.
42. Utzschneider KM, Tong J, Montgomery B, et al. The dipeptidyl peptidase-4 inhibitor vildagliptin improves beta-cell function and insulin sensitivity in subjects with impaired fasting glucose. Diabetes Care. 2008;31:108-113.

43. Scherbaum WA, Schweizer A, Mari A, et al. Efficacy and tolerability of vildagliptin in drug-naive patients with type 2 diabetes and mild hyperglycaemia. Diabetes Obes Metab. 2008;10:675-682.

44. Scherbaum WA, Schweizer A, Mari A, et al. Evidence that vildagliptin attenuates deterioration of glycaemic control during 2-year treatment of patients with type 2 diabetes and mild hyperglycaemia. Diabetes Obes Metab. 2008;10:1114-1124.

45. Rosenstock J, Baron MA, Dejager S, Mills D, Schweizer A. Comparison of vildagliptin and rosiglitazone monotherapy in patients with type 2 diabetes: a 24-week, double-blind, randomized trial. Diabetes Care. 2007;30:217-223.

46. Rosenstock J, Kim SW, Baron MA, et al. Efficacy and tolerability of initial combination therapy with vildagliptin and pioglitazone compared with component monotherapy in patients with type 2 diabetes. Diabetes Obes Metab. 2007;9:175-185.

47. Pi-Sunyer FX, Schweizer A, Mills D, Dejager S. Efficacy and tolerability of vildagliptin monotherapy in drug-naive patients with type 2 diabetes. Diabetes Res Clin Pract. 2007;76:132-138.

48. Pan C, Yang W, Barona JP, et al. Comparison of vildagliptin and acarbose monotherapy in patients with type 2 diabetes: a 24-week, double-blind, randomized trial. Diabet Med. 2008;25:435-441.

49. Goke B, Hershon K, Kerr D, et al. Efficacy and safety of vildagliptin monotherapy during 2-year treatment of drug-naive patients with type 2 diabetes: comparison with metformin. Horm Metab Res. 2008;40:892-895.

50. Foley JE, Sreenan S. Efficacy and safety comparison between the DPP-4 inhibitor vildagliptin and the sulfonylurea gliclazide after two years of monotherapy in drug-naive patients with type 2 diabetes. Horm Metab Res. 2009;41:905-909.

51. Dejager S, Razac S, Foley JE, Schweizer A. Vildagliptin in drug-naive patients with type 2 diabetes: a 24-week, double-blind, randomized, placebo-controlled, multiple-dose study. Horm Metab Res. 2007;39:218-223.

52. Bosi E, Dotta F, Jia Y, Goodman M. Vildagliptin plus metformin combination therapy provides superior 
glycaemic control to individual monotherapy in treatment-naive patients with type 2 diabetes mellitus. Diabetes Obes Metab. 2009;11:506-515.

53. Schweizer A, Dejager S, Bosi E. Comparison of vildagliptin and metformin monotherapy in elderly patients with type 2 diabetes: a 24 -week, double-blind, randomized trial. Diabetes Obes Metab. 2009;11:804-812.

54. Pratley RE, Rosenstock J, Pi-Sunyer FX, et al. Management of type 2 diabetes in treatment-naive elderly patients: benefits and risks of vildagliptin monotherapy. Diabetes Care. 2007;30:3017-3022.

55. Schweizer A, Dejager S, Foley JE, Shao Q, Kothny W. Clinical experience with vildagliptin in the management of type 2 diabetes in a patient population $>/=75$ years: a pooled analysis from a database of clinical trials. Diabetes Obes Metab. 2011;13:55-64.

56. Bolli G, Dotta F, Colin L, Minic B, Goodman M. Comparison of vildagliptin and pioglitazone in patients with type 2 diabetes inadequately controlled with metformin. Diabetes Obes Metab. 2009;11:589-595.

57. Bosi E, Camisasca RP, Collober C, Rochotte E, Garber AJ. Effects of vildagliptin on glucose control over 24 weeks in patients with type 2 diabetes inadequately controlled with metformin. Diabetes Care. 2007;30:890-895.

58. Filozof C, Gautier JF. A comparison of efficacy and safety of vildagliptin and gliclazide in combination with metformin in patients with type 2 diabetes inadequately controlled with metformin alone: a 52-week, randomized study. Diabet Med. 2010;27:318-326.

59. Goodman M, Thurston H, Penman J. Efficacy and tolerability of vildagliptin in patients with type 2 diabetes inadequately controlled with metformin monotherapy. Horm Metab Res. 2009;41:368-373.

60. Ferrannini E, Fonseca V, Zinman B, et al. Fiftytwo-week efficacy and safety of vildagliptin vs. glimepiride in patients with type 2 diabetes mellitus inadequately controlled on metformin monotherapy. Diabetes Obes Metab. 2009;11:157166.

61. Matthews DR, Dejager S, Ahren B, et al. Vildagliptin add-on to metformin produces similar efficacy and reduced hypoglycaemic risk compared with glimepiride, with no weight gain: results from a 2-year study. Diabetes Obes Metab. 2010;12:780789.
62. Gilbert MP, Pratley RE. Efficacy and safety of incretinbased therapies in patients with type 2 diabetes mellitus. Am J Med. 2009;122(suppl.):S11-S24.

63. Nauck MA, Meininger G, Sheng D, Terranella L, Stein PP. Efficacy and safety of the dipeptidyl peptidase-4 inhibitor, sitagliptin, compared with the sulfonylurea, glipizide, in patients with type 2 diabetes inadequately controlled on metformin alone: a randomized, double-blind, non-inferiority trial. Diabetes Obes Metab. 2007;9:194-205.

64. Garber AJ, Schweizer A, Baron MA, Rochotte E, Dejager S. Vildagliptin in combination with pioglitazone improves glycaemic control in patients with type 2 diabetes failing thiazolidinedione monotherapy: a randomized, placebo-controlled study. Diabetes Obes Metab. 2007;9:166-174.

65. Garber AJ, Foley JE, Banerji MA, et al. Effects of vildagliptin on glucose control in patients with type 2 diabetes inadequately controlled with a sulphonylurea. Diabetes Obes Metab. 2008;10:1047-1056.

66. Kikuchi M, Haneda M, Koya D, et al. Efficacy and tolerability of vildagliptin as an add-on to glimepiride in Japanese patients with type 2 diabetes mellitus. Diabetes Res Clin Pract. 2010;89:216-223.

67. Hermansen K, Kipnes M, Luo E, Fanurik D, Khatami $\mathrm{H}$, Stein P. Efficacy and safety of the dipeptidyl peptidase- 4 inhibitor, sitagliptin, in patients with type 2 diabetes mellitus inadequately controlled on glimepiride alone or on glimepiride and metformin. Diabetes Obes Metab. 2007;9:733-745.

68. de Heer J, Holst JJ. Sulfonylurea compounds uncouple the glucose dependence of the insulinotropic effect of glucagon-like peptide 1 . Diabetes. 2007;56:438-443.

69. El Ouaghlidi A, Rehring E, Holst JJ, et al. The dipeptidyl peptidase 4 inhibitor vildagliptin does not accentuate glibenclamide-induced hypoglycemia but reduces glucose-induced glucagon-like peptide 1 and gastric inhibitory polypeptide secretion. J Clin Endocrinol Metab. 2007;92:4165-4171.

70. Buse JB, Henry RR, Han J, Kim DD, Fineman MS, Baron AD. Effects of exenatide (exendin-4) on glycemic control over 30 weeks in sulfonylureatreated patients with type 2 diabetes. Diabetes Care. 2004;27:2628-2635.

71. Marre M, Shaw J, Brandle M, et al. Liraglutide, a once-daily human GLP-1 analogue, added to a sulphonylurea over 26 weeks produces greater 
improvements in glycaemic and weight control compared with adding rosiglitazone or placebo in subjects with type 2 diabetes (LEAD-1 SU). Diabet Med. 2009;26:268-278.

72. Ahren B, Holst JJ, Mari A. Characterization of GLP1 effects on beta-cell function after meal ingestion in humans. Diabetes Care. 2003;26:2860-2864.

73. Holst JJ, Vilsboll T, Deacon CF. The incretin system and its role in type 2 diabetes mellitus. Mol Cell Endocrinol. 2009;297:127-136.

74. Fonseca V, Schweizer A, Albrecht D, Baron MA, Chang I, Dejager S. Addition of vildagliptin to insulin improves glycaemic control in type 2 diabetes. Diabetologia. 2007;50:1148-1155.

75. Fonseca V, Baron M, Shao Q, Dejager S. Sustained efficacy and reduced hypoglycemia during one year of treatment with vildagliptin added to insulin in patients with type 2 diabetes mellitus. Horm Metab Res. 2008;40:427-430.

76. Vilsboll T, Rosenstock J, Yki-Jarvinen $\mathrm{H}$, et al. Efficacy and safety of sitagliptin when added to insulin therapy in patients with type 2 diabetes. Diabetes Obes Metab. 2010;12:167-177.

77. Marfella R, Barbieri M, Grella R, Rizzo MR, Nicoletti GF, Paolisso G. Effects of vildagliptin twice daily vs. sitagliptin once daily on 24hour acute glucose fluctuations. J Diabetes Complications. 2010;24:79-83.
78. Devendra D, Gohel B, Bravis V, et al. Vildagliptin therapy and hypoglycaemia in Muslim type 2 diabetes patients during Ramadan. Int J Clin Pract. 2009;63:1446-1450.

79. Cryer PE. Glucose counterregulation: prevention and correction of hypoglycemia in humans. Am J Physiol. 1993;264:E149-E155.

80. Israelian Z, Szoke E, Woerle J, et al. Multiple defects in counterregulation of hypoglycemia in modestly advanced type 2 diabetes mellitus. Metabolism. 2006;55:593-598.

81. Fruehwald-Schultes B, Kern W, Oltmanns KM, et al. Metformin does not adversely affect hormonal and symptomatic responses to recurrent hypoglycemia. J Clin Endocrinol Metab. 2001;86:4187-4192.

82. Landstedt-Hallin L, Adamson U, Lins PE. Oral glibenclamide suppresses glucagon secretion during insulin-induced hypoglycemia in patients with type 2 diabetes. J Clin Endocrinol Metab. 1999;84:3140-3145.

83. Ahrén B, Schweizer A, Dejager S, et al. Vildagliptin enhances islet responsiveness to both hyper- and hypoglycemia in patients with type 2 diabetes. J Clin Endocrinol Metab. 2009;94:1236-1243.

84. Foley JE, Ligueros-Saylan M, He YL, et al. Effect of vildagliptin on glucagon concentration during meals in patients with type 1 diabetes. Horm Metab Res. 2008;40:727-730. 